\title{
Effects of Harmonic Pollution on Three-Phase Electrical Motors
}

\author{
Eleonora. Darie, Emanuel. Darie
}

\begin{abstract}
This paper presented the effects of the distortion phenomenon of electrical current and electric voltage curves on three-phases electric motors as well as the methods of evaluation of the extra losses from three-phases electric motors due to harmonics. There are also some entries useful for the harmonic analysis of a consumer driven by a three-phase asynchronous motor.
\end{abstract}

Keywords-Deforming Regime, Harmonic Analysis, Power Quality, Three-Phases Electrical Motor.

\section{INTRODUCTION}

$\mathrm{T}$ HE distortion of the voltage and current curves is damaging the equipment of both producers and users of electricity. The results of the presence of harmonics and inter harmonics of electric and / or voltage in electrical networks are [1]: increased losses in electricity transmission and distribution networks; increased losses in consumer electricity networks, overstressing and aging of electrical network and equipment insulation; thermal overload of the neutral conductor in low voltage installations; interference with command and protection signals on power lines, disturbances in telecommunication networks.

The actions (effects) of harmonic distortions on the components of an electro-energetic system are not fully known.

\section{II.EFFECTS ON ELECTRIC MOTORS}

The most important effects due to the presence of harmonics in the electrical network on electric motors are: increased losses in conductors and magnetic materials; increasing the temperature of the windings and the magnetic core, due to additional losses in conductors and magnetic materials; the occurrence of couples with a rotational speed corresponding to the frequency of the harmonics (in the supply voltage curve); reducing the life of electric cars, lowering the efficiency of electric cars.

\section{A. Additional losses due to the flow of harmonic currents}

Harmonic currents and voltages cause high thermal effects due to additional power losses: losses in conductive materials; losses in magnetic materials; dielectric losses [9].

Eleonora. Darie, Technical University of Civil Engineering, Bucharest, Romania (e-mail: eleonora.darie@gmail.com).

Emanuel. Darie, was with Police Academy, Bucharest, Romania. He is now a collaborator of the same university (e-mail: edarie@gmail.com).

\section{B. Analysis of Harmonic Components}

In the voltage curve of the electric motors, there may appear: harmonic ranks: $h=3 \cdot k$ ( $k$ - integer number), they behave like symmetrical zero-sequence (homopolar) sequences; harmonic rank: $h=3 \cdot k+1$, which behaves as the positive (direct) symmetric components; harmonic rank $h$ $=3 \cdot k+2$, which behaves as symmetrical components of negative (indirect). In relation to the rotor rotating at the speed corresponding to the fundamental harmonics, the harmonics of rank $h=3 \cdot k+1$, determines couples in the direction of rotation of the electric machine, and the harmonics of rank: $h=3 \cdot k+2$, causes couples in the opposite direction to the direction of rotation of the electric machine [1].

The operation of non-sinusoidal electric motors is equivalent to the operation of several electric motors (the number of which is equal to the number of harmonics present in the non-sinusoidal supply voltage) coupled to the same axle and rotating at the same speed, only powered by actual value voltages and different frequencies $U_{1}, U_{2}, \ldots, U_{\mathrm{h}}$, respectively $f_{1}, f_{2}, \ldots, f_{\mathrm{h}}$, where $h$ is the rank of the harmonica. Each harmonic will determine active or resilient couples (which are added or subtracted to the main torque generated by the fundamental harmonic) [1].

The presence of current harmonics in the motor windings also leads to an increase in the acoustic noise produced by the engine [1], [9].

\section{Engine Power Denomination}

In accordance with IEC 600034-1: 2010 [6], alternating voltage electric motors must be able to operate smoothly in electrical networks having a harmonic voltage $(F A)$ factor of less than or equal to $2 \%$ and being calculated with the relationship [8]:

$$
F A=\sqrt{\sum_{h=2}^{\infty}\left(\frac{U_{h}}{U_{1}}\right)^{2} \cdot \frac{1}{h}} .
$$

In this relation, the third harmonic is excluded.

If the power supply network is characterized by a greater distortion, it may be necessary to reduce the load on the machine (a denomination of machine power).

A particular problem occurs in the case of electric motors powered by static frequency converters (which produce a strongly distorted voltage), which can lead to strong thermal and mechanical stresses of the electric motor [7]. In these situations, it is necessary to carry out an analysis of the practical possibilities of reducing the perturbations and the load limits of the electric motor. 


\section{POWER QUALITY INDICATORS}

\section{A. Quality indicators of the electrical energy}

The evaluation of harmonics and inter-harmonics of voltage and currents in the electrical networks is based on electricity quality indicators, established according to international standards: EN 50160 [1], [2], CEI 6100-4-30 [2] and CEI 6100-4-7 [1], [2].

The harmonics of the electrical voltage are individually evaluated [4] (by their relative amplitude $U_{\mathrm{h}}(\%)$ ) and global (through the total harmonic distortion factor, THDU), with the help of relationships [1], [4]:

$U_{h}(\%)=\frac{U_{h}}{U_{1}} \cdot 100$.

$T H D U=\frac{\sqrt{\sum_{h=2}^{40}\left(U_{h}\right)^{2}}}{U_{1}}$.

The harmonics of electricity are evaluated by relationships:

$I_{h}(\%)=\frac{I_{h}}{I_{1}} \cdot 100$

$T H D I=\frac{\sqrt{\sum_{h=2}^{40}\left(I_{h}\right)^{2}}}{I_{1}}$.

\section{B. Evaluation and measurement of harmonics}

The most important international standards, which establish the methods, procedures for measuring and evaluating the harmonics and inter harmonics in the electrical networks, as well as the requirements, which must be met by the equipment used for this purpose, are the following: CEI 61000-4-30:208 [3], [5] and CEI 6100-4-7:2002 [3], [6].

Current measurement systems of voltage and currents in electrical networks use numerical techniques to measure analogue sizes and to process measured values. For numerical processing, the analog signals taken from the electrical networks are sampled. The processing of the samples resulting from the measurements for the harmonic analysis of the distorted voltage and current curves is done by means of the Fourier transform (made with discrete values of the analyzed size), called Discrete Fourier Transform (DFT) and a fast processing algorithm, known as Fast Fourier Transform (FFT) [1].

Non-sinusoidal quantities in the power system are defined by a function having the shape:

$$
\begin{aligned}
f(t)=c_{0} & +\sum_{h=1}^{\infty} c_{h} \cdot \sin \left(h \cdot \omega_{1} \cdot t+\varphi_{h}\right)+ \\
& +\sum_{h=1}^{\infty} c_{m} \cdot \sin \left(m \cdot \omega_{1} \cdot t+\beta_{m}\right) .
\end{aligned}
$$

in which: the first part of (6) refers to the harmonics and the second part to the inter-harmonics; $c_{0}$ - continuous component; $c_{h}$ - the amplitude of the harmonic frequency component $f_{h}=h \cdot f_{1} ; \quad \omega_{1}$ - the pulse of the fundamental component $\left(\omega_{1}=2 \cdot \pi \cdot f_{1}\right) ; \varphi_{\mathrm{h}}-$ the phase shift harmonics $h$, to the fundamental; $c_{m}$ - the amplitude of the inter-harmonic frequency component $f_{h}=h \cdot f_{1} ; \beta_{\mathrm{m}}$ - the phasing of the interharmonics $m$, to the fundamental.

\section{IV.ARMONIC ANALYSIS OF A CONSUMER ACTIONED BY A ASYNCHRONOUS THREE-PHASE MOTOR, 400/230 V, 160 KW}

$A$. The voltage recorded on the three power lines is shown in Figure 1.

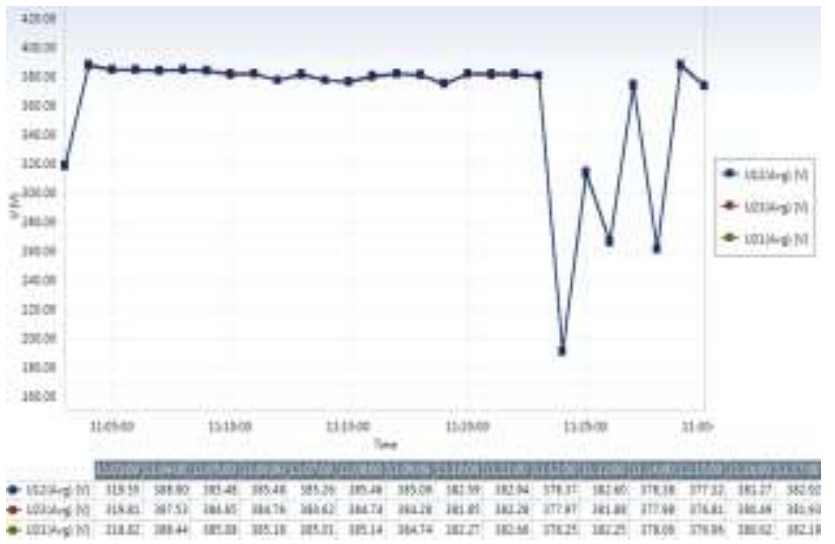

Fig. 1 Variation of the supply voltage (V) with the electrical energy on the three lines, within the time considered.

$B$. The voltage recorded on the three phases is shown in Figure 2.

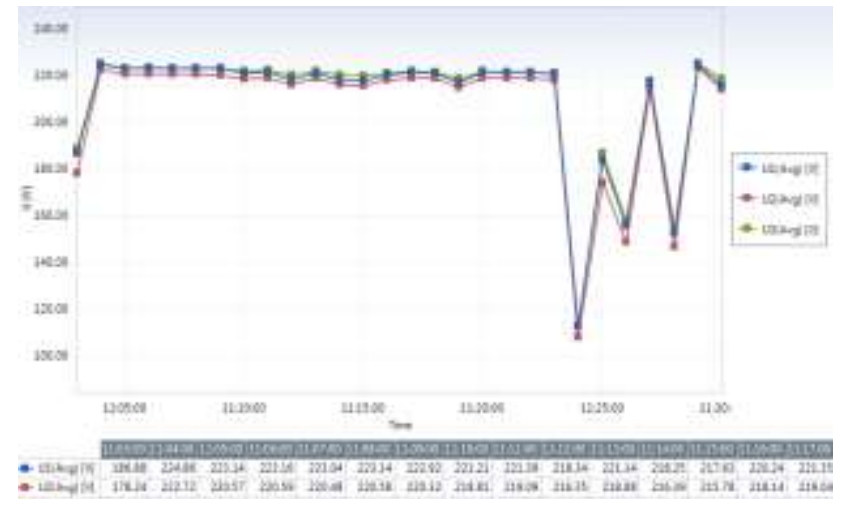

Fig. 2 Variation of the supply voltage (V) with the electrical energy on the three phases, within the time considered. 
C. The voltage recorded on the neutral conductor is shown in Figure 3.

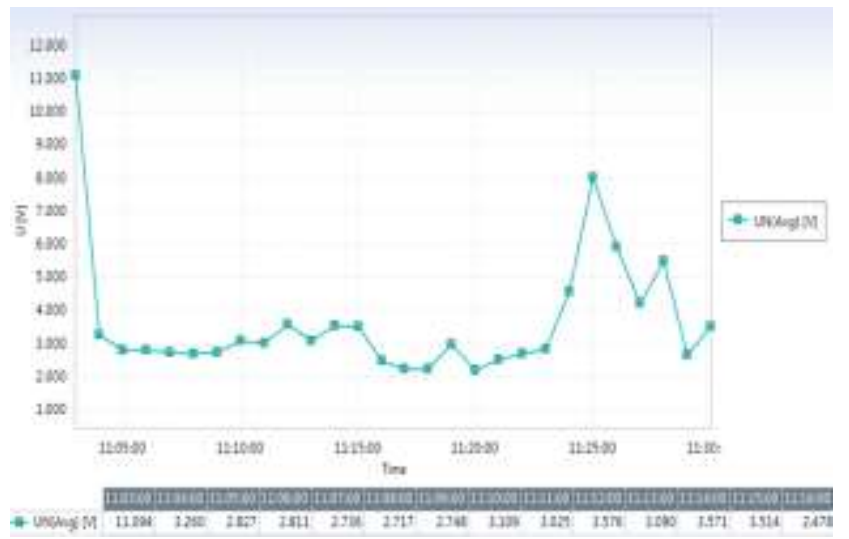

Fig. 3 Voltage variation on the neutral conductor over the time considered.

D. Voltage harmonics of the $3^{\text {rd }}, 5^{\text {th }}, 7^{\text {th }}, 9^{\text {th }}$ and $10^{\text {th }}$ order (expressed as a percentage).

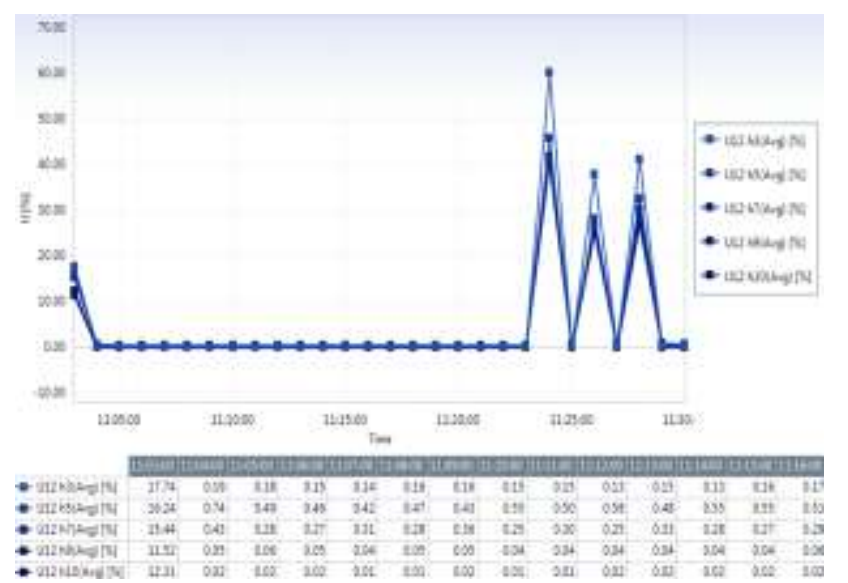

Fig. 4 Voltage harmonics of the $3^{\text {rd }}, 5^{\text {th }}, 7^{\text {th }}, 9^{\text {th }}$ and $10^{\text {th }}$ order (expressed as a percentage).

E. Total harmonic voltage distortion factor THDU (expressed as a percentage) on the three power lines.

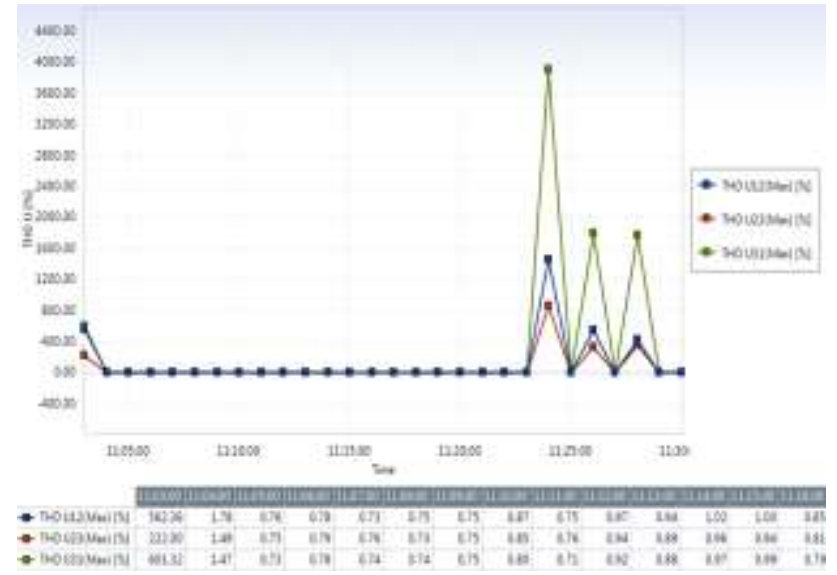

Fig. 5 Total harmonic voltage distortion factor THDU (expressed as a percentage) on the three power lines.
$F$. The currents recorded on the three power lines are shown in Figure 6.

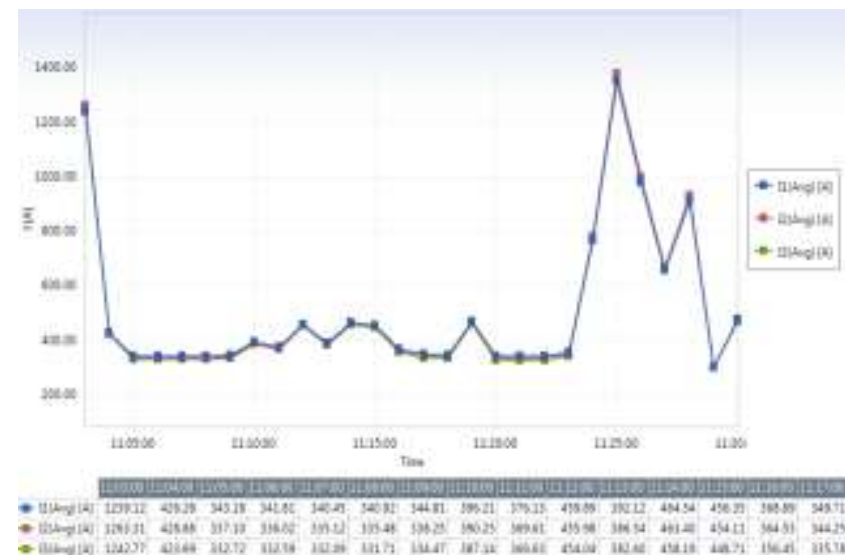

Fig. 6 Variation of the currents (A) on the three power lines within the considered time frame.

G.The current recorded on the neutral conductor is shown in Figure 7.

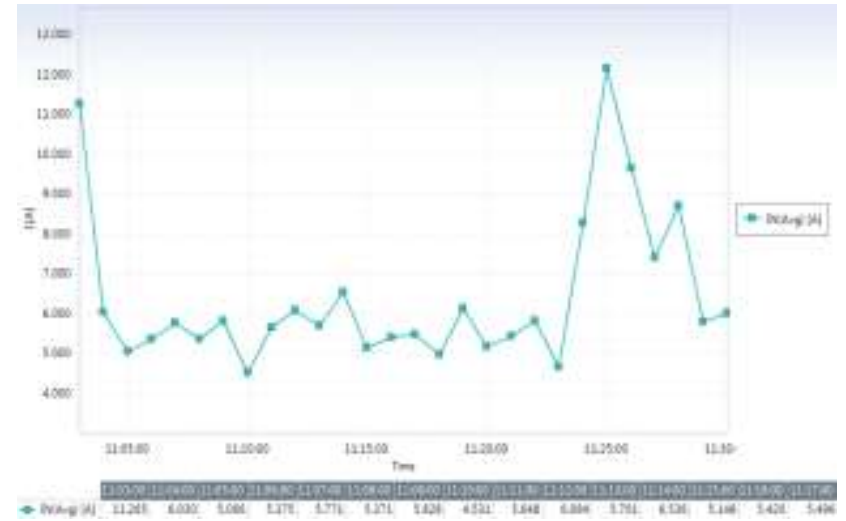

Fig. 7 Current variation (A) on the neutral conductor, within the time interval considered.

H.Current harmonics of the $3^{\text {rd }}, 5^{\text {th }}, 7^{\text {th }}, 9^{\text {th }}$ and $39^{\text {th }}$ order from the current spectrum $I_{1}$ are:

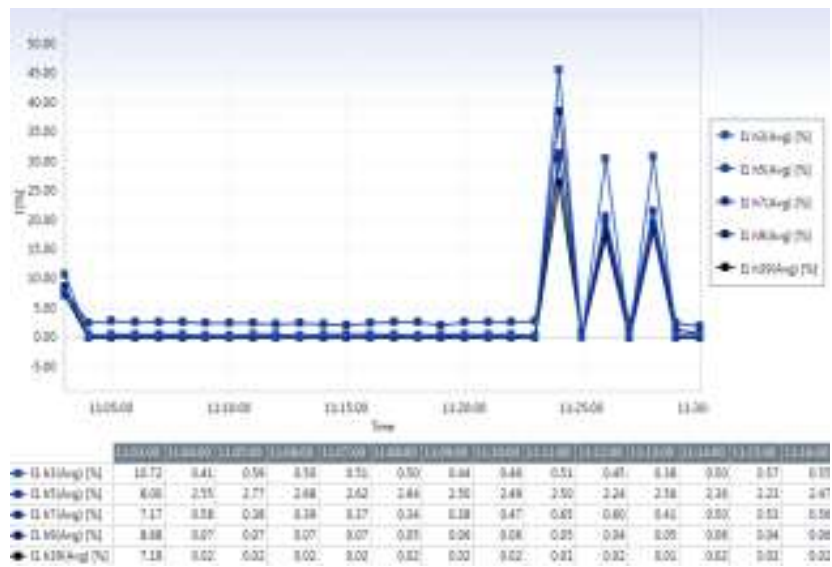

Fig. 8 Current harmonics of the $3^{\text {rd }}, 5^{\text {th }}, 7^{\text {th }}, 9^{\text {th }}$ and $39^{\text {th }}$ order from the current spectrum $I_{1}$ (expressed as a percentage). 
I. The current harmonics of the $2^{\text {nd }}, 4^{\text {th }}, 6^{\text {th }}$, and $40^{\text {th }}$ order, present in the current spectrum $I_{2}$.

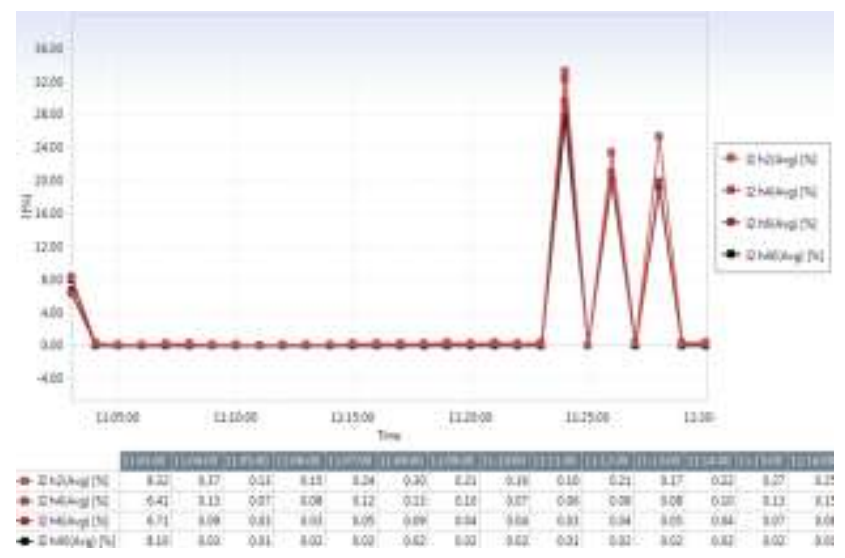

Fig. 9 The current harmonics of the $2^{\text {nd }}, 4^{\text {th }}, 6^{\text {th }}$, and $40^{\text {th }}$ order (expressed as a percentage), present in the current spectrum $I_{2}$.

$J$. The current harmonics of the $2^{\text {nd }}, 3^{\text {rd }}, 4^{\text {th }}, 7^{\text {th }}$, and $9^{\text {th }}$ order, present in the current spectrum $I_{3}$.

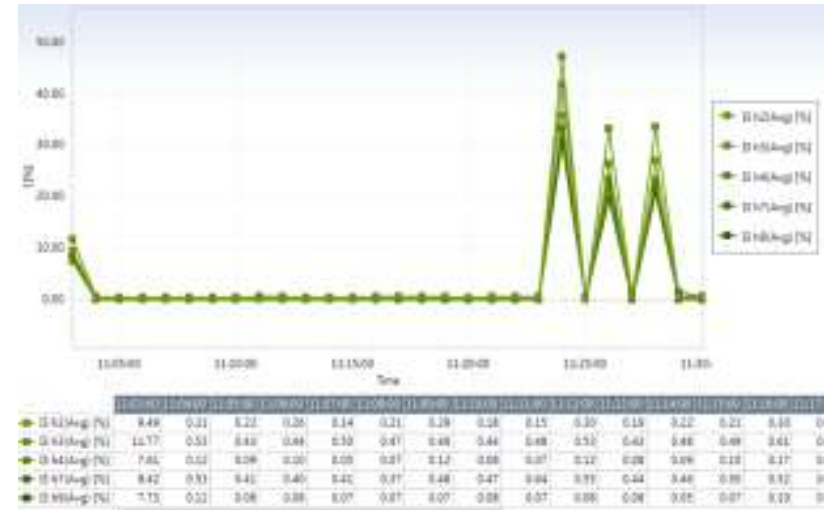

Fig. 10 The current harmonics of the $2^{\text {nd }}, 3^{\text {rd }}, 4^{\text {th }}, 7^{\text {th }}$, and $9^{\text {th }}$ order (expressed as a percentage) present in the current spectrum $\mathrm{I}_{3}$.

$K$. The current harmonics of the $2^{\text {nd }}, 3^{\text {rd }}, 4^{\text {th }}, 7^{\text {th }}$, and $9^{\text {th }}$ order, present in the current spectrum $I_{N}$.

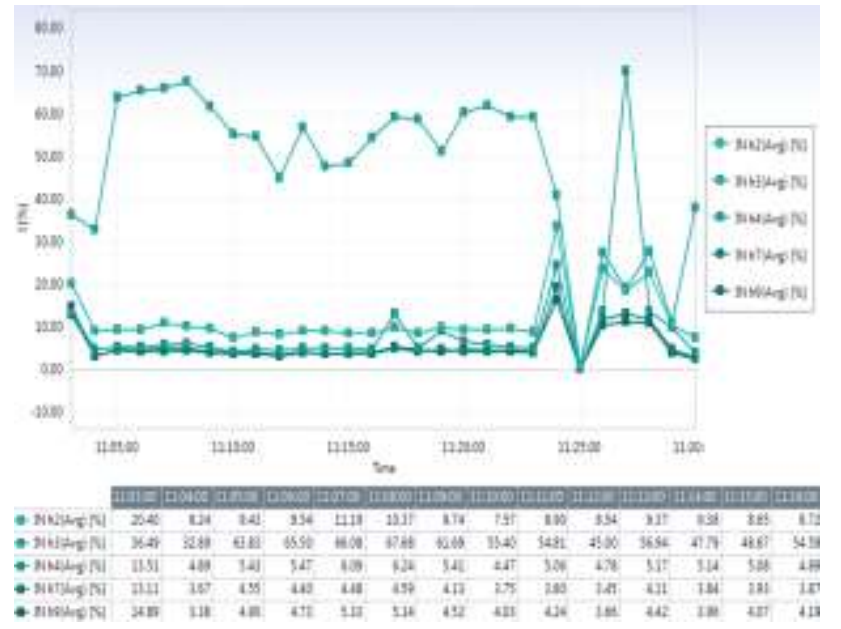

Fig. 11 The current harmonics of the $2^{\text {nd }}, 3^{\text {rd }}, 4^{\text {th }}, 7^{\text {th }}$, and $9^{\text {th }}$ order (expressed as a percentage) present in the current spectrum $I_{N}$.
L. The distortion factor of the electric current, THDI (expressed as a percentage).

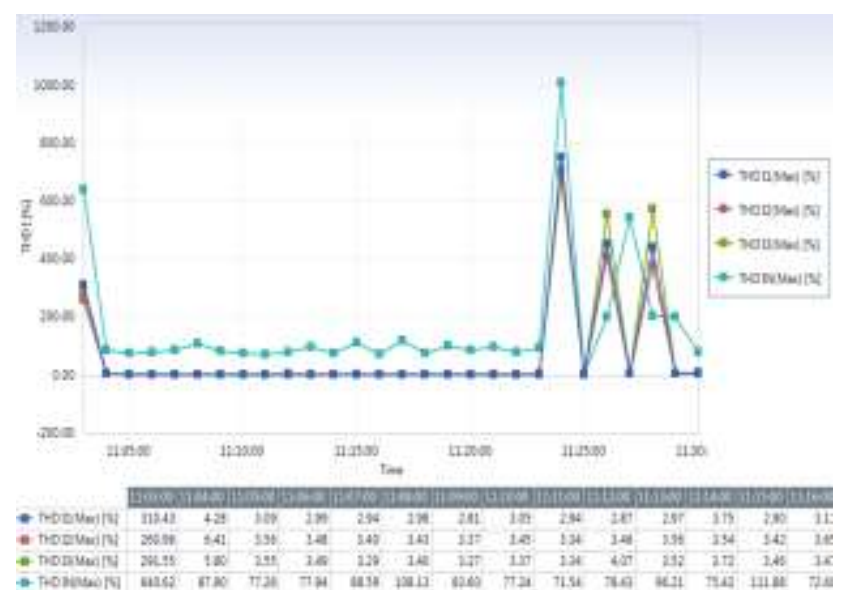

Fig. 12 The distortion factor of the electric current, THDI (expressed as a percentage).

M. Total electric current distortion factor TDDI (expressed as a percentage), of the load.

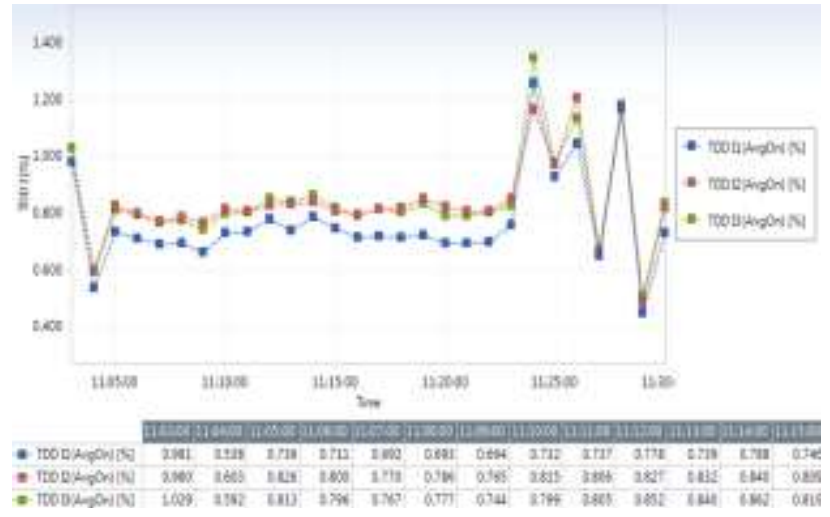

Fig. 13 Total electric current distortion factor TDDI (expressed as a percentage), of the load.

The method of measuring the harmonics is in accordance with the actual regulations in force (the standard: EN 50160, CEI 61000-4-30) and the measurements were made with Power Analyzer (software Metrel Power View, v.3.0).

\section{V.CONCLUSION}

The existence of harmonic currents leads to the increase of the actual values of the currents in the conductors of the electric lines and in particular from the neutral conductor [4].

From the analysis of the measured measurements, it is observed that the limits of the individual voltage harmonics values in the low voltage electric networks, at the supply terminals, for ranges up to 25 (in percent) compared to the fundamental voltage $U_{1}$ (the standard: EN 50160; CEI 610002-2), and the limit values for the harmonics of electricity emitted in low-voltage installations of three-phase equipment's (the standard CEI 61000-2-4), is not fully respected.

It is emphasizes the need to carry out as many measurements as possible (according to the standards and regulations in force) for different time periods (up to one 
week) in order to obtain the largest and most consistent amount of information [4].

Without measurements (it is advisable to use the most efficient analyzers), one cannot: know the real complexity of the deformation phenomenon analyzed; establish measures to attenuate the deforming phenomenon and subsequently evaluate the effectiveness application of the attenuation measures.

\section{REFERENCES}

[1] F. Vatră, P. Postolache a.o., Calitatea energiei electrice. Manual pentru profesioniști. Volumul 2, SIER Publishing House, Bucharest, 2015, ISBN 978-973-87456-4-3.

[2] Vatră, P. Postolache a.o., Calitatea energiei electrice. Manual pentru profesioniști. Volumul 1, SIER Publishing House, Bucharest, 2013, general ISBN 978-973-87456-4-3, volume ISBN: 978-973-87456-5-0.

[3] Vatră, P. Postolache a.o., Calitatea energiei electrice. Manual pentru profesioniști. Volumul 1, SIER Publishing House, Bucharest, 2013, general ISBN 978-973-87456-4-3, volume ISBN: 978-973-87456-5-0.

[4] Iordănescu, I., Postolache, P., Toader, C., Jișa, M., Fenomenul deformant în instalațiile electrice și eficiența măsurilor de atenuare. Ed. AGIR, București, 2012.

[5] Eurelectric, Power Quality in Europeean Electricity Supply Network, Ref. 2002-2700-005.

[6] CEI 610004-30:2008, Electromagnetic Compatibility (EMC) - Part 430: Testing and measurement technique - Power Quality measurements methods.

[7] CEI 610004-30:2008, Electromagnetic Compatibility (EMC) - Part 4-7: Testing and measurement technique - General gide on harmonics and interharmonics measurements, for power supply systems and equipment.

[8] A. Baggini, Z. Hanzelka, Voltage and Currents Harmonics - Chapter 7 from Handbook of Power Quality, John Willey \& Sons, Ltd. 2008, ISBN: 978-0-470-06561-7.

[9] A. Arie, E. Neguș a.o., Poluarea cu armonici a sistemelor electroenergetice funcționând în regim permanent simetric, Editura Academiei, Bucharest, 1994. 